\title{
BMJ Open Protocol for the e-POWUS Project: multicentre blinded-randomised controlled trial of ultrasound speed choice to improve sonography quality in pregnant women with obesity
}

Amélie Delabaere (1) ,1,2 Benoit Chauveau, ${ }^{3}$ Didier Lémery, ${ }^{1,2}$ Amandine Ollier, ${ }^{4}$ Candy Guiguet-Auclair, ${ }^{2,5}$ Charline Mourgues, ${ }^{2,6}$ Anne Legrand ${ }^{1,2}$

To cite: Delabaere A, Chauveau B, Lémery D, et al. Protocol for the e-POWUS Project: multicentre blindedrandomised controlled trial of ultrasound speed choice to improve sonography quality in pregnant women with obesity. BMJ Open 2021;11:e038684. doi:10.1136/ bmjopen-2020-038684

- Prepublication history for this paper is available online To view these files, please visit the journal online (http://dx.doi. org/10.1136/bmjopen-2020038684).

Received 19 March 2020 Accepted 19 May 2021

\section{D) Check for updates}

(c) Author(s) (or their employer(s)) 2021. Re-use permitted under CC BY-NC. No commercial re-use. See rights and permissions. Published by BMJ.

For numbered affiliations see end of article.

\section{Correspondence to} Dr Amélie Delabaere; adelabaere@chuclermontferrand.fr

\section{ABSTRACT}

Introduction During pregnancy, maternal obesity increases the risk of fetal abnormalities. Despite advances in ultrasound imaging, the assessment of fetal anatomy is less thorough among these women. Currently, the construction of ultrasound images uses a conventional ultrasound propagation velocity $(1540 \mathrm{~m} / \mathrm{s})$, which does not correspond to the slower speed of propagation in fat tissue.

The main objective of this randomised study is to compare the completeness of fetal ultrasonography according to whether the operator could choose the ultrasound velocity $(1420,1480$ or $1540 \mathrm{~m} / \mathrm{s})$ or was required to apply the $1540 \mathrm{~m} / \mathrm{s}$ velocity.

Methods and analysis This randomised trial is an impact study to compare a diagnostic innovation with the reference technique. The trial inclusion criteria require that a pregnant woman with obesity be undergoing a fetal morphology examination by ultrasound from $20^{+0}$ to $25^{+0}$ gestational weeks.

Randomisation will allocate women into two groups. The first will be the 'modulable speed' group, in which operators can choose the speed of ultrasound propagation to be considered for the morphological analysis: 1420,1480 or $1540 \mathrm{~m} / \mathrm{s}$. In the second 'conventional speed' group, operators will perform the morphological examination with the ultrasound speed fixed at $1540 \mathrm{~m} / \mathrm{s}$. The adjudication committee, two independent experts, will validate the completeness of each examination and the quality of the images.

Ethics and dissemination This research protocol does not change the standard management. The only possible impact is an improvement of the ultrasound examination by improving the quality of the image and the completeness of morphological examination. The Agence du Médicament et produits de santé approved this study (2018-A03478-47). The anonymised data will be available on request from the principal investigator. Results will be reported in peer-reviewed journals and at scientific meetings.

Trial registration number ClinicalTrials.gov (http://www. clinicaltrials.gov) Registry (NCT04212234).

\section{Strengths and limitations of this study}

- It is the first randomised study offering sonographers a choice in the ultrasound velocity to be used for image construction of morphology scans in pregnant women with obesity.

- The sonographic quality will be evaluated by two experts, independent of the investigators, blinded to the propagation velocity and other patient data.

- The method of performing the ultrasound examination is reproducible in daily practice.

- The primary objective is completeness of the ultrasound examination, which enables the objective assessment of a clear-cut and clinically useful goal.

- The scoring of the sonography quality is subjective.

- The sequence for performing the ultrasound examination in pregnant woman is specifically adapted to French guidelines.

\section{INTRODUCTION}

The increased incidence of obesity is a major health problem that affects all age groups and all social levels, including women of childbearing age. ${ }^{12}$

While obese women are at greater risk of fetal abnormalities, ${ }^{3-7}$ the performance of fetal morphological examination is less thorough despite advances in ultrasound imaging $^{8}$ and the performance of repeated examinations. $^{9-13}$

To construct an image with ultrasound, the equations used the value of the propagation velocity of sound waves. In the human body, this velocity is considered conventionally to be constant and equal to $1540 \mathrm{~m} / \mathrm{s}$, and all manufacturers of ultrasound scanners have used this value since $1977 .{ }^{14-18}$ Nevertheless, the real propagation velocity of ultrasound in fatty tissue is only on the order of $1450 \mathrm{~m} / \mathrm{s}^{17}$ The quality of ultrasound images constructed 
by the ultrasound software depends on insonation depth, energy absorption and dispersion of the ultrasound beam, ${ }^{8}$ as well as on the distance-duration relation, according to the equation $\mathrm{Z}=\mathrm{cT} / 2$ (where $\mathrm{Z}=\mathrm{depth}$, $\mathrm{c}=\mathrm{velocity}$ of ultrasound propagation in a homogeneous medium and $\mathrm{T}=$ duration of the round trip of the wave between its source and target). Construction of an image by the scanner based on the conventional velocity of 1540 $\mathrm{m} / \mathrm{s}$ when the actual velocity of propagation in the tissue studied is slower therefore produces discrepancies in the distances measured, with the reconstructed image of the target represented at a site and scale different from reality. ${ }^{19}$ Speckling is increased, and lateral resolution and contrast are poor, so that a punctate object appears as a segment ('moustache effect'). ${ }^{19}$ The choice of a velocity of $1450 \mathrm{~m} / \mathrm{s}$ for the construction of the image in the presence of fat to improve the image quality was initially suggested in mammary imaging, as the breast is a predominantly adipose organ. ${ }^{19} 20$ To consider the slower sound wave velocity in fat tissue than in other soft tissues (ie, $1450 \mathrm{~m} / \mathrm{s}$ vs $1540 \mathrm{~m} / \mathrm{s}$ ) for image construction should lead to better intrinsic image quality in terms of sharpness and precision. ${ }^{21}$ The main objective of this randomised study is to compare the completeness of fetal ultrasound examinations according to whether the operator could choose to calculate sound wave velocity at 1420,1480 or $1540 \mathrm{~m} / \mathrm{s}$ or was required to apply the $1540 \mathrm{~m} / \mathrm{s}$ velocity.

\section{METHODS AND ANALYSIS Study design}

This blinded-randomised superiority trial is an impact study to compare a diagnostic innovation with the reference technique (figure 1).

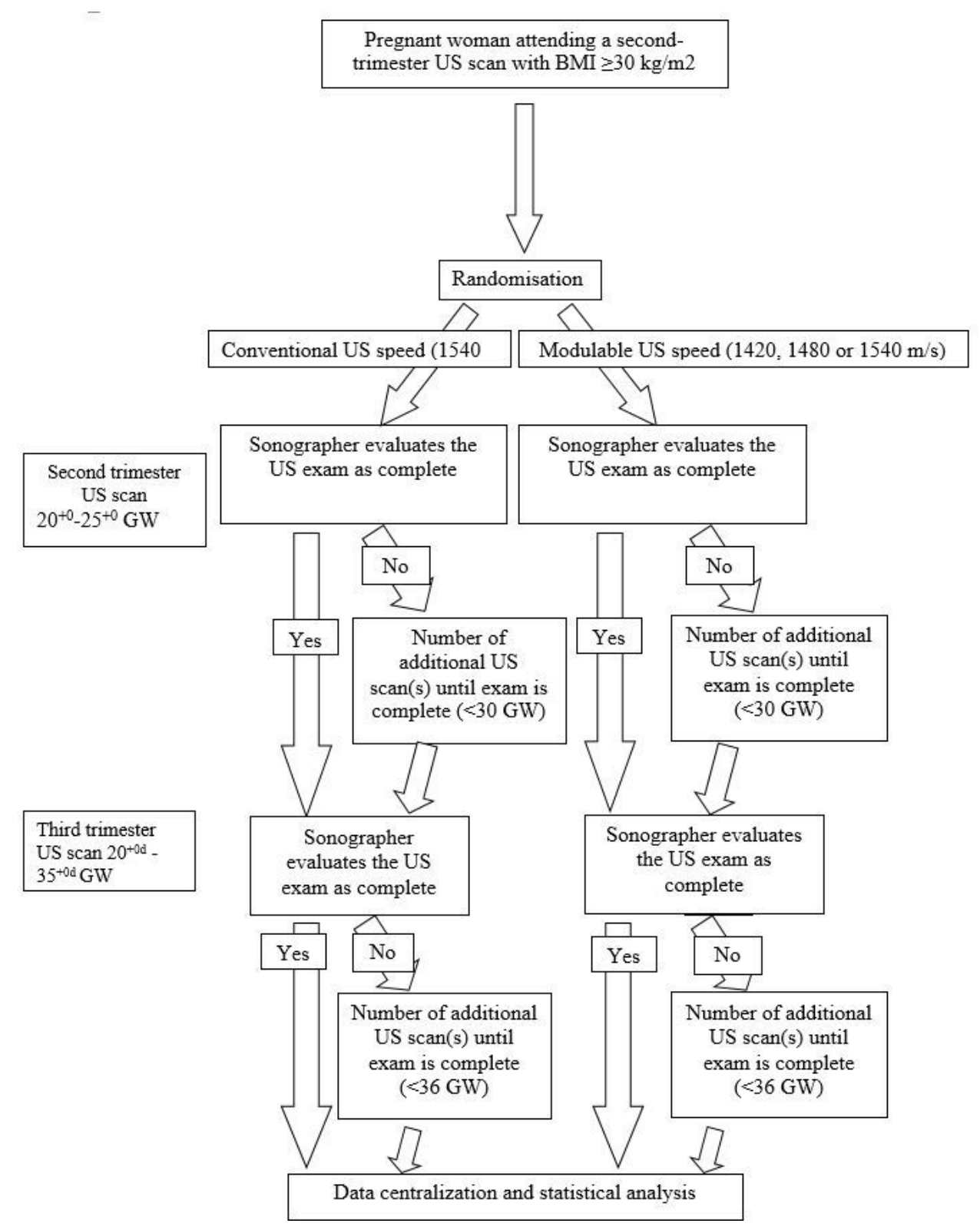

Figure 1 Study design. BMI, body mass index; GW, gestational weeks; US, ultrasound. 


\section{Study population}

The trial inclusion criteria require that only pregnant women with obesity who are undergoing a fetal morphology examination by ultrasound from $20^{+0}$ to $25^{+0}$ gestational weeks (GW) be included.

The exclusion criteria cover any woman who:

- Refuses to have the ultrasound examination or to participate in the study.

- Is a minor or under guardianship/curatorship.

- Has an uncertain or unknown date of conception.

- Had a prepregnancy body mass index (BMI) $<30 \mathrm{~kg} /$ $\mathrm{m}^{2}$.

- Has a fetus with a congenital malformation or an anomaly of the amniotic fluid or the placenta, identified by an ultrasound scan earlier in this pregnancy $\left(<20^{+0} \mathrm{GW}\right)$.

- Is carrying a multiple pregnancy.

- Has a scar of the abdominal, pelvic or uterine wall.

- Has a fibromatous uterus.

The woman's results will not be analysed if the fetus:

- Is diagnosed with a congenital anomaly during the study.

- Dies in utero during the study.

- Is diagnosed with an anomaly of the amniotic fluid or the placenta during the study.

- Is diagnosed as 'small for gestational age' $(<10$ th percentile of estimated weight for gestational age on the curve of the French college of fetal ultrasound).

\section{Study protocol}

Version: 7.0 as of 24 May 2019.

\section{Recruitment}

Women may be recruited if their prepregnancy BMI $\geq 30 \mathrm{~kg} / \mathrm{m}^{2}$ and they are consulting for a second trimester fetal ultrasound examination in one of the study centres. All operators are experienced fetal ultrasonographers and practise in one of the French university hospitals listed below:

- University Hospital Estaing of Clermont-Ferrand.

- Maternity Port-Royal, Cochin hospital group of Paris.

- Croix-Rousse Hospital of the Hospices Civiles of Lyon.

- Woman-Mother Child Hospital of the Hospices Civiles of Lyon.

- University Hospital Arnaud de Villeneuve of Montpellier.

\section{Intervention}

Ultrasound monitoring of pregnancy in France includes three fetal screening examinations, one in each trimester. This examination is considered complete when all the views recommended by the French National Conference of Obstetric and Fetal Ultrasound (CNEOF) have been acquired (figure 2).

When the second trimester ultrasound is performed (between $20^{+0}$ and $25^{+0} \mathrm{GW}$ ), and if the woman meets the inclusion criteria, she will be randomised for the total duration of the study (figure 3 ). Thus, women will be allocated by randomisation to one of two groups:

- A first 'modulable speed' group in which operators may choose to have the image constructed by the scanner apply any of three sound wave propagation speeds $(1420,1480$ or $1540 \mathrm{~m} / \mathrm{s})$ for the morphological analysis.

- A second 'conventional speed' group in which the only sound wave speed used to construct the images for the morphological examination is the conventional speed of $1540 \mathrm{~m} / \mathrm{s}$.
A.

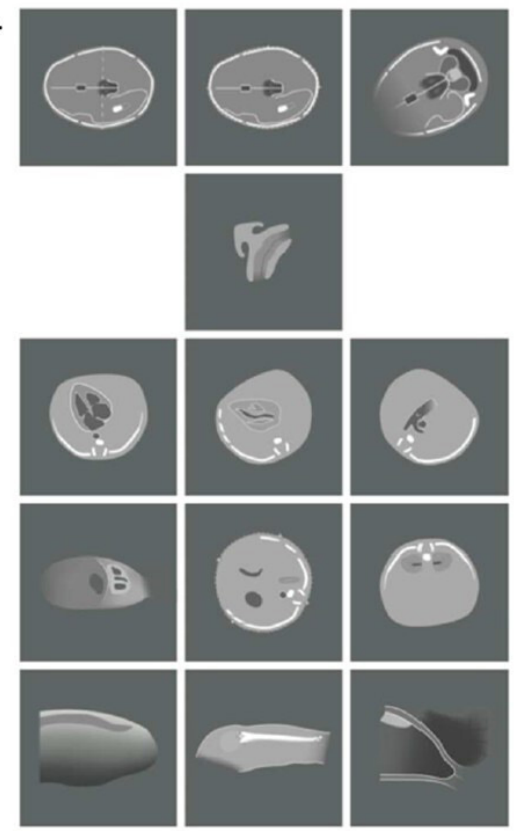

B.
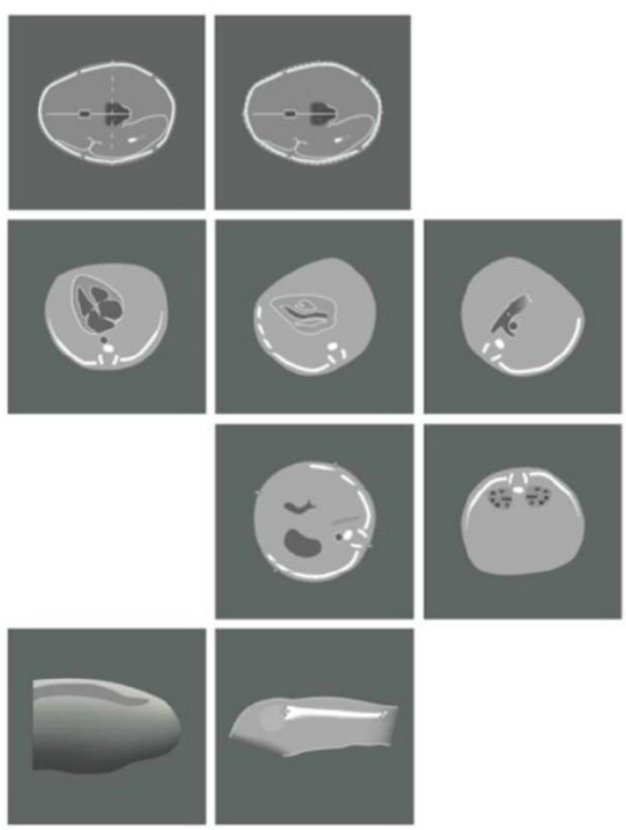


\begin{tabular}{|c|c|c|c|c|c|c|c|c|}
\hline & \multicolumn{8}{|c|}{ STUDY PERIOD } \\
\hline & Enrolment & Allocation & & & -allocation & & & Close-out \\
\hline TIMIPPOINT & $-t 1$ & 0 & $\begin{array}{c}\text { t1 } \\
\text { Second- } \\
\text { trimester } \\
\text { whtresound }\end{array}$ & $\begin{array}{c}\text { t' } \\
\text { Completion } \\
\text { of the } \\
\text { second- } \\
\text { timester } \\
\text { ultrasound } \\
\end{array}$ & $\begin{array}{c}\text { D } \\
\text { Third- } \\
\text { trimester } \\
\text { wltrasonend }\end{array}$ & $\begin{array}{c}D^{\prime} \\
\text { Completion } \\
\text { of the third } \\
\text { trimester } \\
\text { ultresound }\end{array}$ & $\stackrel{L^{3}}{\text { Bivth }}$ & $t^{4}$ \\
\hline ENROLMENT & & & & & & & & \\
\hline Eligibility screen & $\mathrm{X}$ & & & & & & & \\
\hline Informed consent & $\mathrm{X}$ & & & & & & & \\
\hline Allocation & & $\mathrm{X}$ & & & & & & \\
\hline INTERVENTIONS: & & & & & & & & \\
\hline Free choice of ultrasound speed & & & $\leftarrow$ & & & $\longrightarrow$ & & \\
\hline $\begin{array}{l}\text { Standard fixed-speed ultrasound } \\
\text { technique }\end{array}$ & & & & & & $\longrightarrow$ & & \\
\hline ASSESSMENTS & & & & & & & & \\
\hline $\begin{array}{l}\text { Completeness of the ultrasound } \\
\text { gcan }\end{array}$ & & & $\mathrm{x}$ & & $\mathrm{x}$ & & & $\mathrm{x}$ \\
\hline $\begin{array}{l}\text { Comparison of the initial } \\
\text { completeness assessed by the } \\
\text { sonographer with that of the } \\
\text { adjudication committee }\end{array}$ & & & $\mathrm{x}$ & & $\mathrm{x}$ & & & $\mathrm{x}$ \\
\hline $\begin{array}{l}\text { Number of additional } \\
\text { ultrasound appointments } \\
\text { required for completeness of the } \\
\text { gtandard examinations }\end{array}$ & & & & $\mathrm{x}$ & & $\mathrm{x}$ & & $\mathrm{x}$ \\
\hline $\begin{array}{l}\text { Time stamping of each image } \\
\text { and cumulative duration of all } \\
\text { ultrasound examinations }\end{array}$ & & & $\mathrm{x}$ & $\mathrm{x}$ & $\mathrm{x}$ & $\mathrm{x}$ & & $\mathrm{x}$ \\
\hline $\begin{array}{l}\text { Ultrasound speed used for each } \\
\text { image }\end{array}$ & & & $\mathrm{x}$ & $\mathrm{x}$ & $\mathrm{x}$ & $\mathrm{x}$ & & $\mathrm{x}$ \\
\hline $\begin{array}{l}\text { Strategies deployed by } \\
\text { sonographers to improve the } \\
\text { conditions of the ultrasound } \\
\text { examination }\end{array}$ & & & $\mathrm{x}$ & $\mathrm{x}$ & $\mathrm{x}$ & $\mathrm{x}$ & & $\mathrm{x}$ \\
\hline $\begin{array}{l}\text { Standardiged measurements of } \\
\text { adipose tigsue thichness and } \\
\text { probe-amniotic fluid distance }\end{array}$ & & & $\mathrm{x}$ & $\mathrm{x}$ & $\mathrm{x}$ & $\mathrm{x}$ & & $\mathrm{x}$ \\
\hline $\begin{array}{l}\text { Position of the fetur and } \\
\text { placenta }\end{array}$ & & & $\mathrm{x}$ & $\mathrm{x}$ & $\mathrm{x}$ & $\mathrm{x}$ & & $\mathrm{x}$ \\
\hline $\begin{array}{l}\text { Incremental cost-effectiveness } \\
\text { ratio }\end{array}$ & & & & & & & & $\mathrm{x}$ \\
\hline
\end{tabular}

Figure 3 Time schedule of participant enrolment, interventions and visits.

During this examination, the morphological analysis of the fetus will be performed according to the standardised sections recommended by national and international guidelines. ${ }^{22-24}$ The duration of each examination will be recorded and evaluated by the time elapsed between the first and last recorded image.

For each inclusion, the following data will be collected: for the mother, year of birth, geographical origin, number of pregnancies, parity, BMI and date of initiation of pregnancy; and for the operator, the number of years of practice.

For each ultrasound examination, the following data will be collected:

- Woman's weight on that day.

- Gestational age.

- Application of a cosmetic product in the preceding 48 hours.

- Patient's position at the start of the examination.

- Standardised measurements with the probe midway between the umbilicus and the pubis, performed only during the first ultrasound examination of the second and of the third trimester (figure 4):

- Adipose tissue thickness (ATT): distance between the probe and muscle fascia.

- Distance between the probe and amniotic fluid (PAF).

- Fetal and placental positions.

- Amount of amniotic fluid.
- Organ-specific scanning plane (ssp) measurements for each image recommended by the CNEOF (figure 4):

- ssp-ATT.

- Distance between the probe and the target organ.

- Completeness of acquisition of each image recommended by the CNEOF.

- Ultrasound speed used for each image.

- Need to change the maternal position (lateral decubitus, right or left).

- Need to use the vaginal probe in the umbilicus or vagina.

- Presence or absence of fetal anomaly.

- Completeness of the examination, evaluated by the operator.

- Cost of the examination, from the point of view of the French health insurance fund.

- Examination time.

When the second trimester ultrasound examination is considered complete, the pregnant woman will be seen by the same operator for the third trimester scan (between $30^{+0}$ and $35^{+0} \mathrm{GW}$ ), as described below. If it is not considered complete, the woman will be asked to return to repeat it as many times as necessary until it is complete, always with the same operator.

During the standard third trimester ultrasound scan between $30^{+0}$ and $35^{+0} \mathrm{GW}$, the images recommended by CNEOF must be acquired by the same sonographer as during the second trimester scan, with the same data 


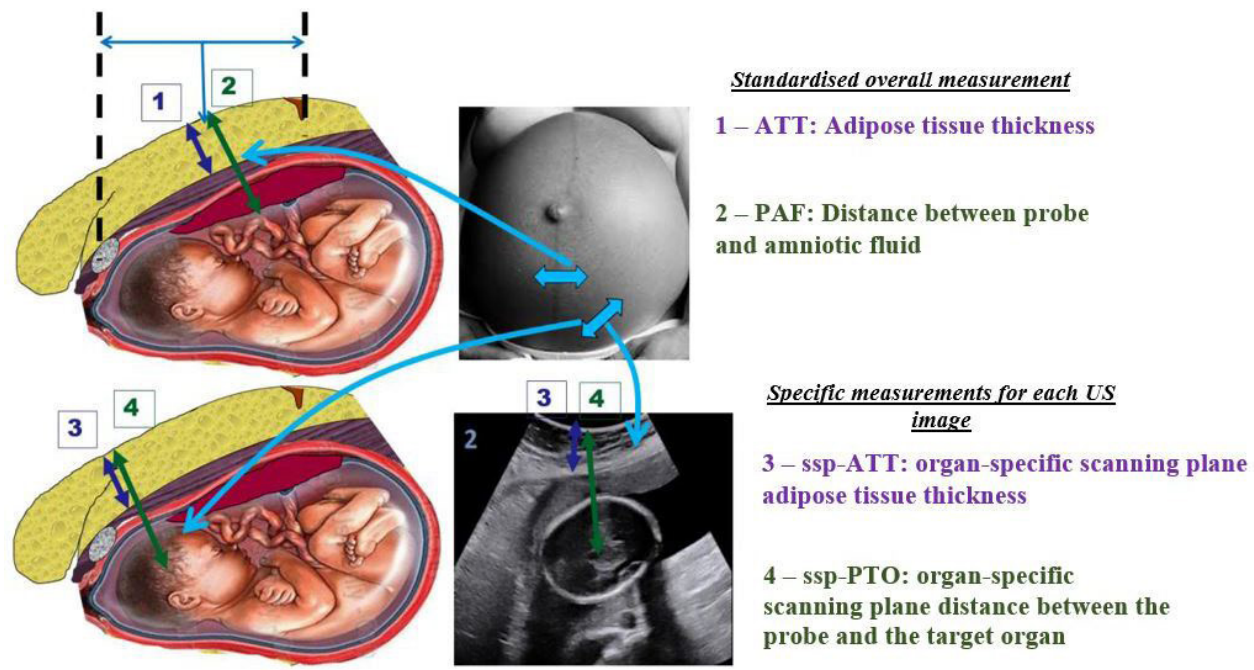

Figure 4 Standardised measurements taken halfway between the umbilicus and the pubis, performed during the first ultrasound (US) appointment of the second and of the third trimester: adipose tissue thickness (ATT) - distance between probe and muscle fascia; distance between probe and amniotic fluid (PAF). Organ-specific measurements for each ultrasound image recommended by the CNEOF: organ-specific scanning plane (ssp) ATT; ssp distance between the probe and the target organ (PTO). CNEOF, French National Conference of Obstetric and Fetal Ultrasound.

collected for each of the specific third trimester images recommended by the CNEOF. Similarly, in the event of incompleteness, the women will be asked to return for completion, but not after $36^{+6}$ GW.

In both randomisation groups, fetal biometrics will be measured exclusively at an ultrasound speed of 1540 $\mathrm{m} / \mathrm{s}$ and according to CNEOF criteria since no reference curve has yet been developed for biometric data obtained at sound wave speeds other than $1540 \mathrm{~m} / \mathrm{s}$. Standardised abdominal wall thickness measurements (ATT and PAF) will also be performed at a sound wave speed of $1540 \mathrm{~m} / \mathrm{s}$.

The scanner used will be the Supersonic Imagine, Model AIXPLORER with a CE marking for obstetrics. It will be used with an abdominal curvilinear probe of 1-6 MHz. Each sonographer can choose all other ultrasound settings according to their personal preference.

Data will be collected about the birth (date and mode of delivery) and the child's status at birth (vital status, weight, height, head circumference and presence of a congenital malformation).

The case report forms will be completed electronically with Clinsight randomisation software.

\section{Randomisation, patient allocation and blinding}

The patients will be allocated into one of the two parallel arms by randomisation by blocks of four to balance the number of parturients in each arm. Because ultrasound is an operator-dependent examination, randomisation will be stratified by the sonographer to limit this operator effect: each sonographer will examine the same number of women in each arm. Women will thus be randomised not only to the study arm but also to the sonographer, so that their follow-up ultrasound will be performed by the same operator throughout the pregnancy.

Women will be masked to their allocation group in this study. The operators will run the ultrasound device programme according to the randomisation arm and must necessarily know if the programme allows speed modulation or not, since they will be able to use this option to optimise the subjective quality of the ultrasound images.

The standardised fetal planes produced during each scan will be exported in an anonymised form to a sharing platform for this study (Tricefy), with the acquisition speed of each plane deleted. Two experts, independently of the investigators and of each other, will validate the completeness of the first ultrasound examination at each trimester and the anatomical quality of the images (compliance with CNEOF recommendations) by applying the Salomon score criteria, ${ }^{25}$ adapted to the CNEOF recommendations (tables 1 and 2). They will be blinded to the image acquisition speed. Their assessments will be entered in Clinsight by using the patient's participation number. The experts will not have access to the collected ultrasound examinations.

\section{Objectives}

Primary objective

Among women with obesity undergoing ultrasound examinations in the second and third trimesters of pregnancy, we seek to evaluate the effect on examination completeness of the operator's ability to choose the sound wave propagation speed $(1420,1480$ or $1540 \mathrm{~m} / \mathrm{s})$, compared with completeness with the standard fixed-speed ultrasound technique $(1540 \mathrm{~m} / \mathrm{s})$.

\section{Secondary objectives}

- Evaluate the accuracy of the assessment of 'examination completeness' assessed by an ultrasound operator in current practice.

- Describe in detail the procedures for performing the additional ultrasound examinations at the subsequent 


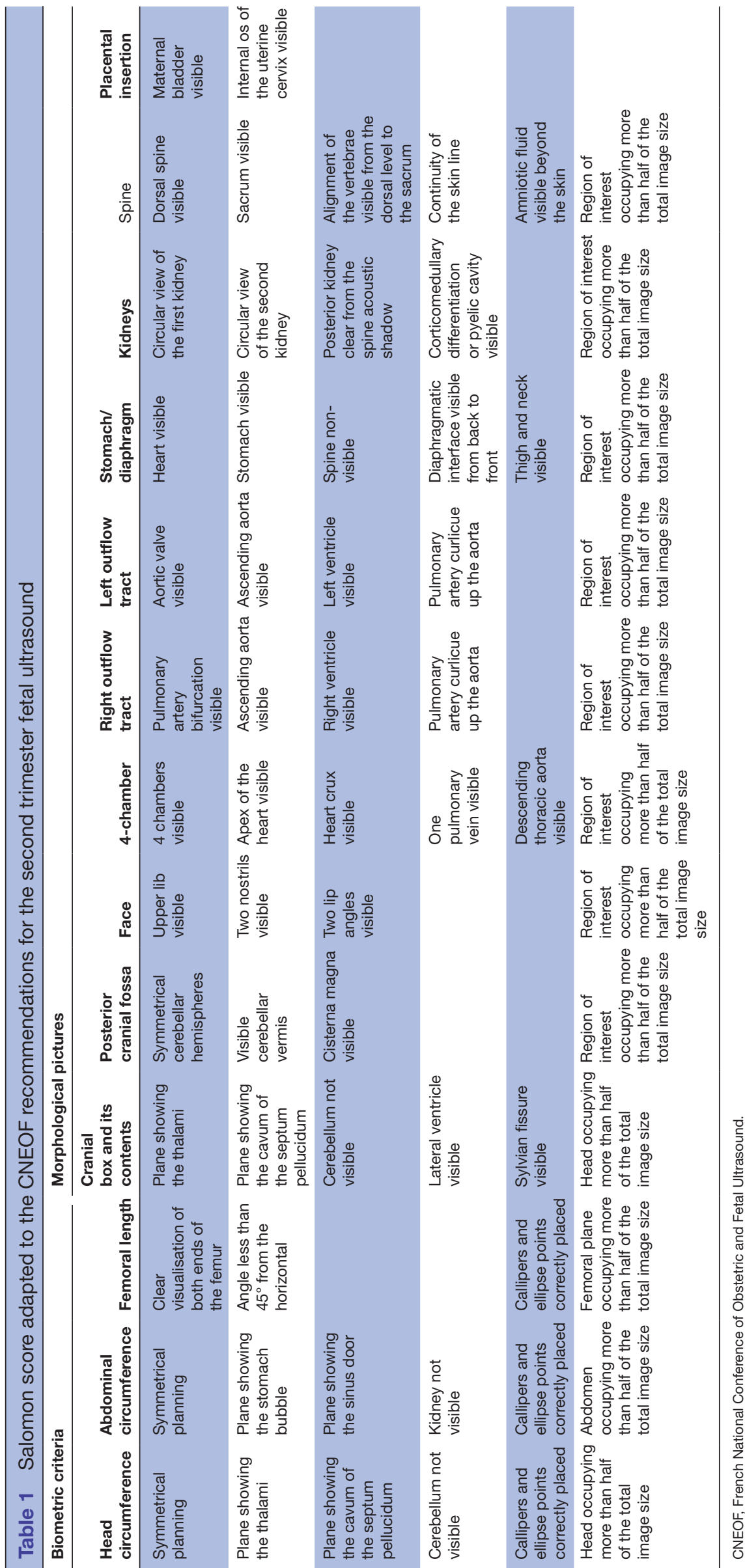




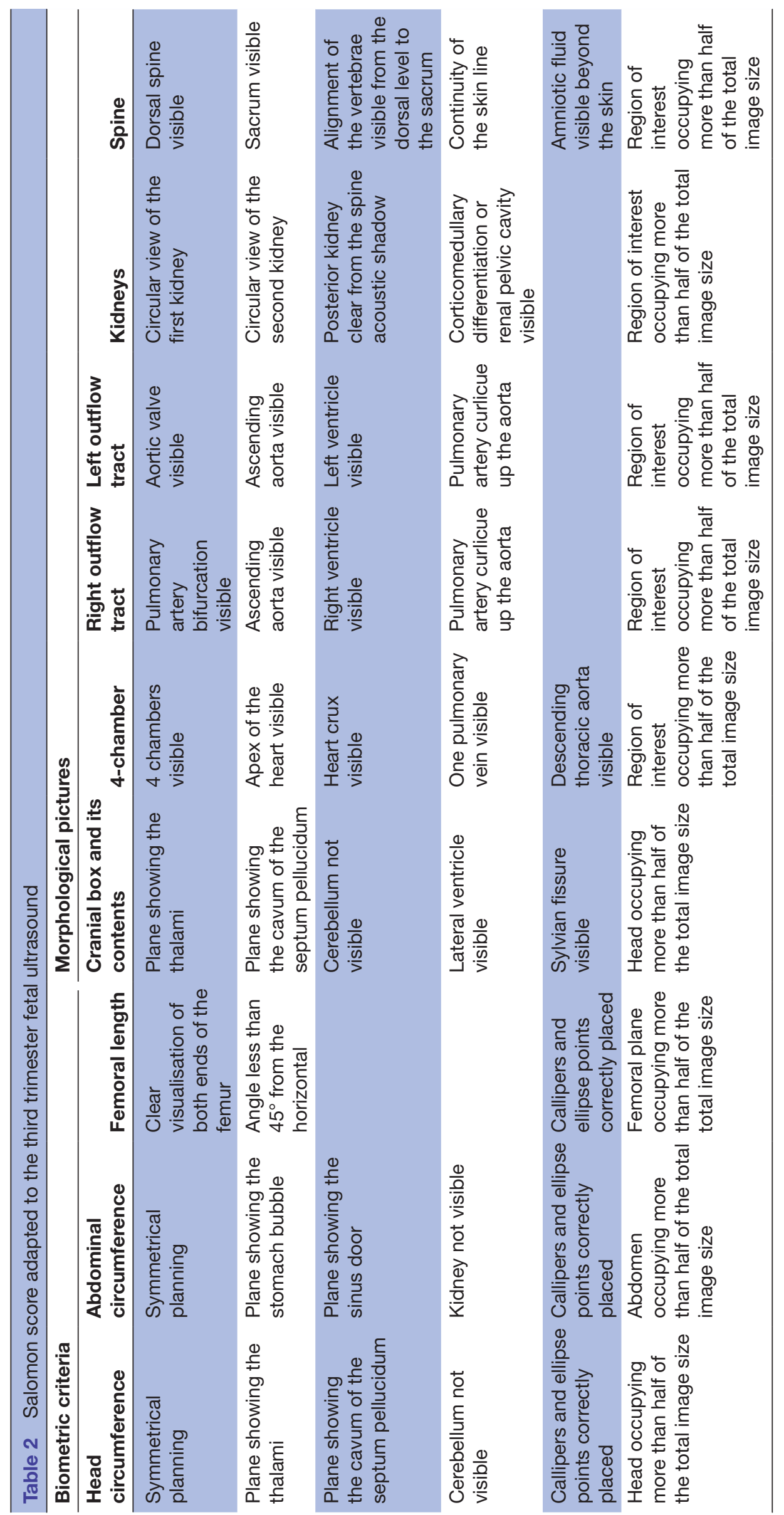


appointments necessary to complete the two standard examinations in both groups.

- Identify possible strategies sonographers can deploy to improve the conditions of the ultrasound examination.

- Evaluate the economic impact, from both the hospital and health insurance perspectives, of modifying the parameter 'sound wave tissue propagation speed' to improve ultrasound performance in pregnant women with obesity.

\section{Study endpoints}

\section{Primary outcome}

The completeness of the ultrasound scan is the primary outcome. It will be derived from the two experts' assessments of each standard ultrasound for antenatal monitoring (the first appointment at or after $20^{+0} \mathrm{GW}$ and the first at or after $30^{+0} \mathrm{GW}$ ) in both groups. This completeness will be established by the independent reading of the ultrasound images by the two experts, masked to both the other's judgement and the randomisation group. An examination will be considered complete by the adjudication committee if all of the images recommended by the CNEOF are acquired.$^{26}$ The initial concordance between experts will be quantified and any discrepancies will be resolved consensually.

\section{Secondary outcomes}

- Compare the initial completeness assessed by the sonographer with that of the adjudication committee.

- Number of additional ultrasound appointments required for completeness of the standard second and third trimester examinations.

- Time stamping of each image and cumulative duration of all ultrasound examinations.

- Ultrasound speeds used for each image.

- Strategies deployed by sonographers to improve the ultrasound examination (maternal position, probes, etc).

- Standardised measurements of ATT and PAF distance.

- Position of the fetus and placenta.

- For economic analysis: incremental cost-effectiveness ratio (ICER).

\section{Patient and public involvement}

The research protocol does not modify standard management; there is no need to prohibit participation in other research or to apply an exclusion period. Neither patients nor sonographers receive any compensation. This is indeed a routine examination.

\section{Sample size calculation}

Sample size was calculated based on the completeness rate of second trimester ultrasound scans estimated by Fuchs $e t a l^{11}(70.4 \%)$. With an assumed completion ratio of $80 \%$ in the intervention group (ie, modulable speed), a minimum calculated sample size of 640 would be required to receive a power level of $90 \%$ with an $\alpha$ of
5\%. The statistical software used was SAS software (V.9.4; SAS Institute).

\section{Statistical analysis}

A $\kappa$ coefficient will be calculated to evaluate inter-rater agreement between the two experts on the adjudication committee.

The statistical test will be one tailed for the main outcome.

The first step will be a univariate analysis. The completeness of the ultrasound examination at each time point will be compared between the two groups with a $\mathrm{X}^{2}$ or Fisher's exact test.

The multivariable analysis will be conducted with a general linear mixed model. Group and gestational age at ultrasound examination will be included as fixed factors. The Tukey-Kramer method will be used to evaluate interaction between these two factors; if it is positive for interaction, the analysis will be stratified by group. Sonographers will be included in the analysis as a random effect, given that the ultrasound examination is sonographer dependent.

To evaluate the operators' assessment of the completeness of the examination, we will calculate sensitivity, specificity, and positive and negative predictive values, using completeness assessed by the adjudication committee as the reference.

The strategies sonographers used to improve the conditions for the ultrasound examination will be compared between the two groups for each scanning plane. Univariate analysis will use the $\mathrm{X}^{2}$ or Fisher's exact test for categorical variables and the Student's t-test or Mann-Whitney test for continuous variables. Multivariable analysis will be performed with logistic regression or linear models. Sonographers will be included in the model as a random effect.

The analysis will be performed according to intention to treat.

Statistical analyses will be performed with SAS software (V.9.4).

\section{Economic analysis}

Two perspectives will be adopted for the economic analysis-that of the hospital and that of the health insurance fund. The duration of the examination and the procedures coded will be compared in the intervention and control groups to determine the cost-effectiveness of the two types of measures (conventional vs modular/optimal velocity).

From the hospitals' point of view, the direct medical costs will be taken into account, calculated by microcosting from the number and duration of examinations. Time spent by the sonographers will be valued by their hourly salary to calculate the gains or opportunity costs. We will conduct a sensitivity analysis that incorporates different assumptions for scanner depreciation costs, according to the material acquisition possibilities and commercial sales policies. The effectiveness will be 
measured by the completeness of the examination during the first ultrasound appointment in the second and the third trimesters. The ICER will be calculated and a costefficiency plan will be used to present the results.

From the health insurance point of view, the costs considered will be the reimbursed costs at the conventional (official basis for reimbursement) prices, depending on the number and type of ultrasound examinations performed. The efficiency criterion will also be the completeness of the examination during the first ultrasound appointment of the second and the third trimesters.

\section{Data Monitoring Safety Committee}

The only possible impact (and the subject of the study) is an improvement in the ultrasound examination and its efficiency by improving the quality of the image to increase the likelihood of a complete scan at the first appointment in both the second and third trimesters.

French law and regulations do not require a Data Monitoring Safety Committee for human research involving minimal risks and constraints. Rather, the law and reporting required for routine care, standard health surveillance and pharmacovigilance apply to this type of study.

\section{Data storage and management}

The case report forms will be completed electronically with the Clinsight randomisation software, verified locally in each centre by the sonographer and a clinical research associate, and then centralised by the primary investigation centre. Centralised quality control will also take place. It will be carried out by a clinical research assistant from the trial sponsor. This control will take place according to the following plan: a first early visit will take place in each centre after five inclusions then every 6 months according to the rate of inclusions.

During the study, the data collected from individuals included in the study and transmitted to the project sponsor by investigators or the clinical research associate shall be anonymised. Under no circumstances will they disclose the names or addresses of the persons concerned.

An inclusion number will be assigned to each patient included by the Clinsight software. The images will be anonymised during their loading onto the Tricefy platform. Only the patient's inclusion number will be visible on images there; it will serve as the key to the result of the expert assessment. Only the experts on the adjudication committee will have access to the ultrasound images on the platform, and this access is personal and temporary for the duration of the study.

The sponsor shall ensure that each person who is included in the study has given her written consent to access the individual data concerning her that are necessary for quality control.

The project sponsor is responsible for obtaining the agreement of all parties involved in the research to ensure direct access to all research sites, source data, source documents and reports for the purpose of quality control and audit by the sponsor. Investigators shall make available the documents and individual data necessary for the monitoring, quality control and audit of research involving human subjects to persons authorised to have access to these documents in accordance with the laws and regulations in force in France.

The case report forms completed during this study will be kept for 15 years by the principal investigator, within the Public Health Department of the University Hospital of Clermont-Ferrand.

\section{Ethics and dissemination}

The first patient inclusion was on 2 December 2019, and we hope to recruit 128 patients in each centre for a total of 640 within 24 months of the first recruitment.

Patients will be informed in a complete and fair manner of the objectives and constraints of the study, the possible risks involved, the necessary surveillance and safety measures, their right to refuse to participate and the possibility of withdrawing at any time. The investigator will obtain the free, informed and written consent of the patient before including her in the study.

The investigator undertakes to conduct this study in accordance with Good Clinical Practices and the public health law in force in France. The protocol complies with the Declaration of Helsinki. The number of ethics committee approval for this study is 2018A03478-47, approved by the independent Protection of Persons Committee number 19.05.09. This multicentre, randomised, parallel-group trial is registered at http:// www.clinicaltrials.gov. All significant changes to the protocol will be validated by this committee and will be documented at http://wwwclinicaltrialsgov.

The anonymised data will be available on request from the principal investigator. The data collected will be centralised and stored on a server at the study coordinating centre (Clermont-Ferrand), where they will be extracted, analysed and used. The data will be divulged only after the joint accord of the principal investigator and the sponsor. The results will be the subject of scientific communications and publications. Authorship eligibility will follow the Recommendations for the Conduct, Reporting, Editing and Publication of Scholarly Work in Medical Journals, 2015.

\section{DISCUSSION}

Several studies have shown that it is currently difficult to obtain complete and good quality fetal ultrasound examinations in pregnant women with obesity. ${ }^{1127}$

In a preliminary study (POWUS), we showed that considering the parameter of sound wave tissue propagation speed, which is slower in fatty tissue, made it possible to improve the constitutive image of four planes of standardised anatomical fetal sections in the second trimester of pregnancy in women with a preconceptional BMI $>30$. Experts with extensive experience in ultrasound examinations were asked to rate the quality of the images obtained 
by applying either a 'slow' (1480-1420 m/s) or 'standard' $(1540 \mathrm{~m} / \mathrm{s})$ sound wave speed for the construction of the images obtained in these patients. They showed a significant preference for the images obtained with the slower ultrasound speed. ${ }^{21} 28$

No study has yet evaluated the impact, in this evergrowing obese population, of this new machine adjustment parameter on the efficiency of ultrasound monitoring of pregnancy in terms both of the ability to perform a complete fetal morphological screening and of the duration or repetition of the ultrasound examinations necessary to complete it.

Our main hypothesis is that the use of variable speed ultrasound will produce more complete initial examinations than the standard-speed ultrasound examinations of pregnant women with obesity. We aimed to reach the same completeness for obese women in the intervention group as that obtained in other studies for women who are not obese. Several studies have demonstrated that the feasibility of a complete scan is $57 \%-70 \%$ in obese groups and $70 \%-80 \%$ in non-obese groups. ${ }^{11} 28$ Sample size was evaluated based on the upper range of completeness in both groups, given that those proportions come from a French centre and reflect the performance of French ultrasonographers. Nonetheless, this sample size is available only for second trimester ultrasounds; to our knowledge, no study has evaluated completeness at the third trimester. Our secondary hypothesis is that ultrasound operators consider the examination to be complete even if the image quality is not always fully satisfactory in this difficult situation. Other strategies might also help to improve the quality of ultrasound examinations. The use of variable speed ultrasound should reduce the number of additional ultrasound examinations and the economic impact of ultrasound performance in pregnant women with obesity.

\section{Author affiliations}

${ }^{1}$ Obstetrics and Gynaecology, Clermont-Ferrand University Hospital Center, Clermont-Ferrand, France

${ }^{2}$ EA 4681, PEPRADE, Clermont University, Auvergne University, Clermont-Ferrand, France

${ }^{3}$ Radiology, Clermont-Ferrand University Hospital Center, Clermont-Ferrand, France ${ }^{4}$ CRECHE, Clermont-Ferrand University Hospital Center, Clermont-Ferrand, France

${ }^{5}$ Public Health Department, Clermont-Ferrand University Hospital Center, ClermontFerrand, France

${ }^{6}$ Public Health Department, Clermont-Ferrand University Hospital, Clermont-Ferrand, France

Contributors AD designed/wrote this protocol, conducted a previous study on this subject and is the principal investigator. BC designed/wrote this protocol and conducted a previous study on this subject. DL designed/wrote this protocol and conducted previous studies on this subject. A0 was responsible for setting up and monitoring the study. CG-A performed the statistical analyses. CM performed the economic analyses. AL designed/wrote this protocol, conducted previous studies on this subject and supervised the statistical analyses.

Funding This study is funded by an inter-regional clinical research hospital programme (PHRC IR 2018 DELABAERE).

Competing interests None declared.

Patient and public involvement Patients and/or the public were not involved in the design, or conduct, or reporting, or dissemination plans of this research.
Patient consent for publication Not required.

Provenance and peer review Not commissioned; externally peer reviewed.

Open access This is an open access article distributed in accordance with the Creative Commons Attribution Non Commercial (CC BY-NC 4.0) license, which permits others to distribute, remix, adapt, build upon this work non-commercially, and license their derivative works on different terms, provided the original work is properly cited, appropriate credit is given, any changes made indicated, and the use is non-commercial. See: http://creativecommons.org/licenses/by-nc/4.0/.

ORCID iD

Amélie Delabaere http://orcid.org/0000-0001-6871-9044

\section{REFERENCES}

1 Flegal KM, Kruszon-Moran D, Carroll MD, et al. Trends in obesity among adults in the United States, 2005 to 2014. JAMA 2016;315:2284-91.

2 Zeitlin J, Mohangoo A, Cuttini M, et al. The European perinatal health report: comparing the health and care of pregnant women and newborn babies in Europe. J Epidemiol Community Health 2009;63:681-2.

3 Stothard KJ, Tennant PWG, Bell R, et al. Maternal overweight and obesity and the risk of congenital anomalies: a systematic review and meta-analysis. JAMA 2009;301:636-50.

4 Nuthalapaty FS, Rouse DJ. The impact of obesity on obstetrical practice and outcome. Clin Obstet Gynecol 2004;47:898-913. discussion 980-981.

5 Marchi J, Berg M, Dencker A, et al. Risks associated with obesity in pregnancy, for the mother and baby: a systematic review of reviews. Obes Rev 2015;16:621-38.

6 Shaw GM, Velie EM, Schaffer D. Risk of neural tube defect-affected pregnancies among obese women. JAMA 1996;275:1093-6.

7 Werler MM, Louik C, Shapiro S, et al. Prepregnant weight in relation to risk of neural tube defects. JAMA 1996;275:1089-92.

8 Paladini D. Sonography in obese and overweight pregnant women: clinical, medicolegal and technical issues. Ultrasound Obstet Gynecol 2009;33:720-9.

9 Hendler I, Blackwell SC, Bujold E, et al. The impact of maternal obesity on midtrimester sonographic visualization of fetal cardiac and craniospinal structures. Int J Obes Relat Metab Disord 2004;28:1607-11.

10 Hendler I, Blackwell SC, Bujold E, et al. Suboptimal secondtrimester ultrasonographic visualization of the fetal heart in obese women: should we repeat the examination? J Ultrasound Med 2005;24:1205-9. quiz 1210-1211.

11 Fuchs F, Houllier M, Voulgaropoulos A, et al. Factors affecting feasibility and quality of second-trimester ultrasound scans in obese pregnant women. Ultrasound in Obstetrics \& Gynecology 2013;41:40-6.

12 Dashe JS, Mclntire DD, Twickler DM. Effect of maternal obesity on the ultrasound detection of anomalous fetuses. Obstet Gynecol 2009;113:1001-7.

13 Thornburg LL, Miles K, Ho M, et al. Fetal anatomic evaluation in the overweight and obese gravida. Ultrasound Obstet Gynecol 2009;33:670-5.

14 Szabo TL. Chapter 1 - Introduction. In: Diagnostic ultrasound imaging: inside out. 2nd edn. Academic Press, 2014: 1-37. http:// www.sciencedirect.com/science/article/pii/B978012396487800001X

15 Nelson TR, Pretorius DH. The Doppler signal: where does it come from and what does it mean? AJR Am J Roentgenol 1988;151:439-47.

16 Jensen JA. Medical ultrasound imaging. Prog Biophys Mol Biol 2007;93:153-65.

17 Wells PNT. Ultrasonic imaging of the human body. Rep Prog Phys 1999;62:671-722.

18 Carson PL. Biomedical ultrasonics. By P.N.T. Wells, Ph.D., Academic Press, Inc. London, Copyright 1977. 635 pages. \$46.90. J Clin Ultrasound 1978;6:126-7.

19 Napolitano D, Chou C-H, McLaughlin G, et al. Sound speed correction in ultrasound imaging. Ultrasonics 2006;44 Suppl 1:e43-6.

20 Piccoli CW, Forsberg F. Advanced ultrasound techniques for breast imaging. Semin Roentgenol 2011;46:60-7.

21 Barr DB, Ananth CV, Yan X, et al. Pesticide concentrations in maternal and umbilical cord sera and their relation to birth outcomes in a population of pregnant women and newborns in New Jersey. Sci Total Environ 2010;408:790-5.

22 Chauveau B, Auclair C, Legrand A, et al. Improving image quality of mid-trimester fetal sonography in obese women: role of ultrasound propagation velocity. Ultrasound Obstet Gynecol 2018;52:769-75. 
23 American Institute of Ultrasound in Medicine. AIUM practice guideline for the performance of obstetric ultrasound examinations. $J$ Ultrasound Med 2013;32:1083-101.

24 Salomon LJ, Alfirevic Z, Berghella V, et al. Practice guidelines for performance of the routine mid-trimester fetal ultrasound scan. Ultrasound Obstet Gynecol 2011;37:116-26.

25 Viossat P, Ville Y, Bessis R, et al. [Report of the French Comité national technique de l'échographie de dépistage prénatal (CNTEDP)--Recommendations for second line prenatal ultrasound] Gynecol Obstet Fertil 2014;42:51-60.
26 Moussa HN, Alrais MA, Leon MG, et al. Obesity epidemic: impact from preconception to postpartum. Future Sci OA 2016;2:FSO137.

27 Salomon LJ, Winer N, Bernard JP, et al. A score-based method for quality control of fetal images at routine second-trimester ultrasound examination. Prenat Diagn 2008;28:822-7.

28 Dashe JS, Mclntire DD, Twickler DM. Maternal obesity limits the ultrasound evaluation of fetal anatomy. J Ultrasound Med 2009;28:1025-30. 